\title{
Reports
}

Ecology, 89(11), 2008, pp. 2973-2979

(C) 2008 by the Ecological Society of America

\section{PERSISTENCE OF SPATIAL VARIANCE AND SPATIAL PATTERN IN THE ABUNDANCE OF A SUBMERGED PLANT}

\author{
Raymond H. G. KLaAsSen ${ }^{1}$ and Bart A. Nolet \\ Department of Plant-Animal Interactions, Netherlands Institute of Ecology (NIOO-KNAW), \\ Royal Netherlands Academy of Arts and Sciences, P.O. Box 1299, 3600 BG Maarssen, The Netherlands
}

\begin{abstract}
Organisms usually benefit from heterogeneous conditions, but, by doing so, may reduce the degree of heterogeneity. The question therefore arises how heterogeneity is maintained. We investigated within-year spatiotemporal patterns in a monospecific stand of a submerged plant (fennel pondweed, Potamogeton pectinatus), with the novelty that we distinguished between different forms of heterogeneity: spatial variance (the frequency distribution of densities) and spatial pattern (the spatial distribution of densities). We repeatedly measured plant biomass that was affected by swan predation, winter mortality, and summer regrowth. Spatial variance was enhanced mostly by swan foraging, despite the fact that swans appear to exploit patches to the same threshold level. Spatial pattern, which had vanished after swan foraging, reestablished due to spatial pattern in winter mortality and was further enhanced by plant regrowth. We found that variance and pattern each have their own temporal dynamics and are maintained by different biological processes. We therefore advocate that it is pivotal to distinguish between variance and pattern in the study of spatial heterogeneity.

Key words: Cygnus columbianus bewickii; density dependence; herbivory; heterogeneity; macrophyte; optimal foraging behavior; plant-animal interactions; Potamogeton pectinatus; spatial scale; vegetation patterns.
\end{abstract}

\section{INTRODUCTION}

In recent years it has become increasingly clear that for many problems we cannot ignore the fact that the world is heterogeneous in space (Sparrow 1999). Spatial heterogeneity is by no means "unnecessary complexity" (Pickett and Cadenasso 1995); the general notion is that organisms benefit under heterogeneous conditions (Sparrow 1999), both on the individual and on the population level (Fortin et al. 2005, Fryxell et al. 2005, Klaassen et al. 2006a,b). Spatial heterogeneity in food abundance (i.e., patchiness), for example, provides a forager with an opportunity to bias foraging effort toward areas that are, on average, richer in resources (Valone and Brown 1989, Klaassen et al. 2006b). Smallscale patchiness allows a forager that strategically regulates time in patches as well as movement between patches to achieve a higher energy gain rate (Klaassen et

Manuscript received 13 June 2007; revised 6 May 2008; accepted 29 May 2008. Corresponding Editor: C. Galen.

${ }^{1}$ Present address: Department of Animal Ecology, Lund University, Ecology Building, 22362, Lund, Sweden.

E-mail: raymond.klaassen@zooekol.lu.se al. 2006a), whereas patchiness at the landscape scale allows mobile foragers to compensate for local and temporal variability in resource abundance, facilitating long-term population persistence (Fryxell et al. 2005). Accordingly, for conservation of animal populations it is vital to understand how heterogeneity is maintained in the ecosystem. This problem is particularly interesting in study systems where heterogeneity does not simply reflect heterogeneity in habitat characteristics (so where the template is homogeneous; Bascompte and Sole 1998), thus where heterogeneity is the result of some form of self-organization (Rietkerk et al. 2002).

Spatial heterogeneity consists of spatial variance, i.e., the frequency distribution of densities, and spatial pattern, i.e., the spatial distribution of densities ( $\mathrm{Li}$ and Reynolds 1995, Wiens 2000). Variance and pattern are linked by the fact that pattern cannot exist without variance, but on the contrary there can be variance without pattern (i.e., a random spatial configuration; Tenhumberg et al. 2001). Obviously, variance and pattern can only persist if supporting effects are stronger than counteracting effects (Hutchings 1997, Adler et al. 2001). 

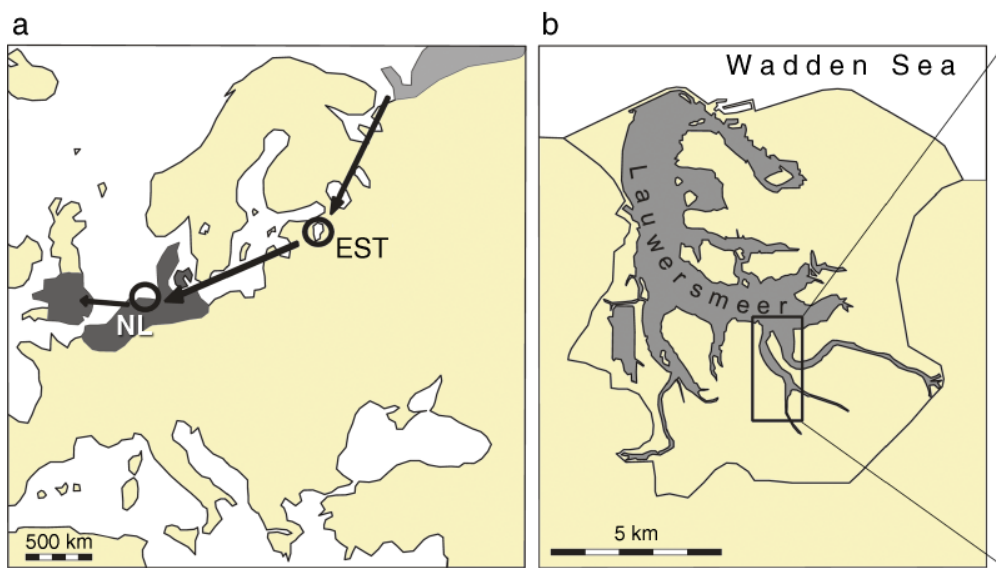

C

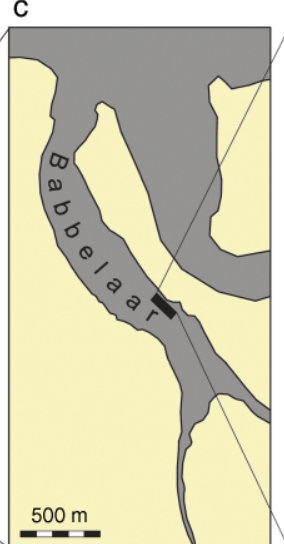

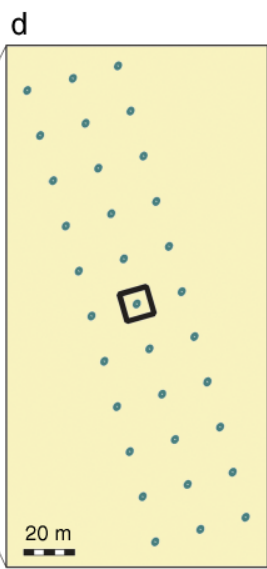

FIG. 1. Schematic representation of the migratory flyway of the Bewick's Swan Cygnus columbianus bewickii, including details about the positioning of the study site and study plots. (a) Autumn situation of the western Palaearctic migratory flyway of the Bewick's Swan. This subspecies breeds in northern Russia (Pechora Delta, light gray shading) and winters in western Europe (United Kingdom-Netherlands-Denmark, dark gray shading). In autumn most swans make stopovers in Estonia (EST) and The Netherlands (NL) (circles) (Beekman et al. 2002). (b) Map of the Lauwersmeer, the most important autumn stopover site in the north of The Netherlands. The area is an embanked estuary and consists of a network of creeks. (c) Map of the Babbelaar, the creek where our study was conducted. The small black rectangle indicates the study area where all plots were positioned. Note that all plots were located on the same (northwestern) side of the creek. (d) Position of the $10 \times 10 \mathrm{~m}$ plot (square) in relation to the 33 squares (circles) (see Methods).

Here we study spatiotemporal patterns in the abundance of a submerged plant, fennel pondweed Potamogeton pectinatus (L.). This is a pseudo-annual macrophyte that survives the winter via belowground tubers (Van Wijk 1988, Santamaría and RodríguezGironés 2002). In autumn (September) the distribution of tubers is strongly heterogeneous (Klaassen et al. 2006a), despite the fact that pondweed occurs in a nearmonospecific stand and on a template that is relatively homogeneous regarding abiotic factors (see Appendix A). The marked spatial variance and spatial pattern in tuber abundance allows the migratory Bewick's Swan Cygnus columbianus bewickii (Yarrell), that relies on submerged plants at migratory stopovers, to achieve a higher energy gain rate (Klaassen et al. 2006a). An enhanced energy intake rate at stopover sites is thought to be pivotal for the swans to successfully complete their migratory journeys (Hedenström and Alerstam 1998). Our study system is the last refueling station for the swans, before they arrive at the wintering grounds (Nolet et al. 2006b; Fig. 1). The dependency of the swans on spatial heterogeneity in their food distribution is especially interesting because foraging itself has an enormous impact on the abundance of plants (Adler et al. 2001, Klaassen et al. 2006a, Nolet et al. 2006b).

We are interested in how spatial variance and spatial pattern in the abundance of tubers develop throughout the year, and whether three important biological processes in the pondweed's life cycle act the same on variance and on pattern. These processes are (1) "plant growth" (the production of tubers in summer), (2) "swan foraging" (the feeding on tubers by swans in autumn), and (3) "winter mortality" (the decomposition of tubers in winter) (Jonzén et al. 2002, Nolet 2004; Fig. 2). We monitored the natural development of variance and pattern at a small spatial scale, equal to the foraging scale or grain of swans (Wiens 1989, Van Eerden et al. 1997, Klaassen et al. 2006b). We illustrate here how spatial variance and spatial pattern in pondweed tuber abundance are affected by the different biological processes, and thus how heterogeneity is maintained in this study system.

\section{Methods \\ Study site}

Data were collected in the Lauwersmeer, a shallow freshwater lake in The Netherlands $\left(53^{\circ} 22^{\prime} \mathrm{N}, 06^{\circ} 13^{\prime} \mathrm{E}\right.$; Fig. 1). In parts $<0.7 \mathrm{~m}$ deep (750 ha) fennel pondweed grows from April to August. Tubers are mainly formed in August (Santamaría 2002, Santamaría and Rodríguez-Gironés 2002). In October the lake is visited by 1500-7000 Bewick's Swans (peak numbers; Beekman et al. 1991).

\section{Sampling}

Tubers were sampled by taking $40 \mathrm{~cm}$ deep cores (diameter $10 \mathrm{~cm}$ ) and sieving the sediment through a 3$\mathrm{mm}$ sieve. Tubers were dried at $70^{\circ} \mathrm{C}$ for $72 \mathrm{~h}$ and weighed individually to the nearest $0.001 \mathrm{~g}$. Tuber abundance is expressed as dry mass biomass density (grams per square meter).

\section{Spatial variance}

Tuber biomass densities were recorded in 33 squares $\left(1 \times 1 \mathrm{~m}, 12 \mathrm{cores} / \mathrm{m}^{2}\right)$, arranged in a regular $3 \times 11$ array (20 $\mathrm{m}$ between squares) in September $(2001,2002,2003$, 2004), November (2001, 2003, 2004), and March (2002, 


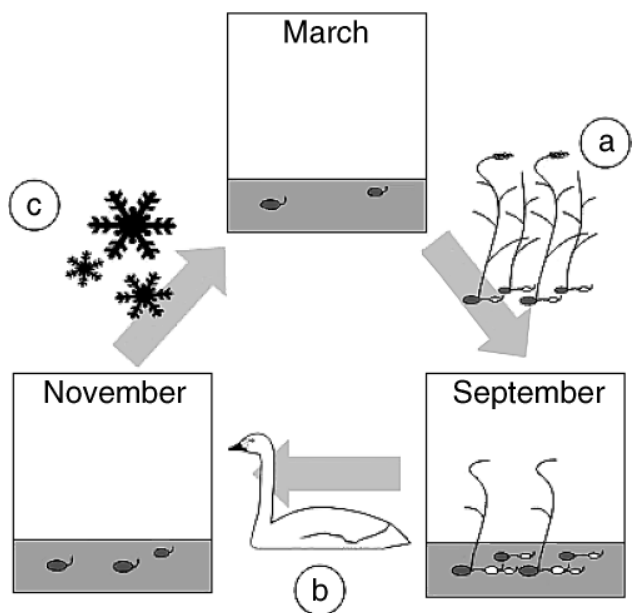

FIG. 2. Scheme of the life cycle of fennel pondweed (Potamogeton pectinatus). Processes that affect spatial heterogeneity in the abundance of pondweed tubers are (a) plant growth (April-August), (b) swan foraging (October), and (c) winter mortality (December-February). We sampled tuber biomass densities in March, September, and November.

2003, 2004). In 2002 the majority of pondweed tubers did not sprout within the study area, possibly as a result of an exceptionally warm period in February 2002 (R. H. G. Klaassen and B. A. Nolet, personal observation), resulting in extremely low tuber densities in September 2002. Because no swans visited the area in October, we did not sample in November 2002. A distance of $20 \mathrm{~m}$ between squares ensures that biomass densities are independent (for none of the sampling occasions could a positive correlation be detected between the densities in squares that were $20 \mathrm{~m}$ apart $\left(R^{2}=0.00-0.07, P=0.08-0.96, n=10\right.$; see also Nolet and Mooij [2002]). For every sampling episode we calculated the average and the coefficient of variation $(\mathrm{CV})$ of biomass density.

\section{Spatial pattern}

Tuber biomass densities were recorded in each $1 \times 1 \mathrm{~m}$ square $\left(12\right.$ cores $\left./ \mathrm{m}^{2}\right)$ within a $10 \times 10 \mathrm{~m}$ plot in
September (2001, 2003), November (2001, 2003), and March (2002, 2003, 2004). For abovementioned reasons no sampling was conducted in September and November 2002. For different lag distances (i.e., distances between squares), the magnitude of spatial autocorrelation was quantified by Moran's $I$ index (Moran 1950, Sawada 1999). In order to summarize the degree of spatial pattern for a certain sampling occasion we summed the absolute Moran's $I$ indices for all lag distances (1-9 m; Adler et al. 2001). Spatial relationships were visualized by autocorrelograms, i.e., a plot of the Moran's I index against lag distance (Adler et al. 2001).

\section{Abiotic factors}

All study plots were located on the northeastern shore of the same creek $(400 \times 1200 \mathrm{~m}$; Fig. 1). Throughout this area the water depth (standardized against the regulated water table) varied from 26.5 to $46.5 \mathrm{~cm}$. The granulometric composition of the sediment was described along a single axis (using principal components analysis; see Nolet et al. 2001), which correlated most strongly with the silt fraction (percentage soil particles $<$ $63 \mu \mathrm{m}$; Nolet et al. 2001). Within the study area the silt fraction varied from 1.5 to $4.8 \%$ (95\% confidence limit), which equals only $6 \%$ of the variation in silt fraction observed in the whole creek. Additional information about the (low) variation in abiotic factors throughout the study area is presented in Appendix A.

\section{RESUlts}

Tuber biomass densities were highest just after the growing season, as a result of a strong increase due to plant growth (Fig. 3a). Tuber biomass production in the summer was constant despite different initial (March) densities (see Fig. 4), indicating that per capita pondweed growth is depressed at higher densities (Fig. 4a). Swan foraging and subsequently winter mortality strongly decreased tuber biomass density (Fig. 3a). The exploitation by swans is a function of initial (September) density (Fig. 4b). From the exploitation pattern we can infer that swans exploit patches down to a threshold density of $8.5-13.0 \mathrm{~g} / \mathrm{m}^{2}$ (negative of regression intercept
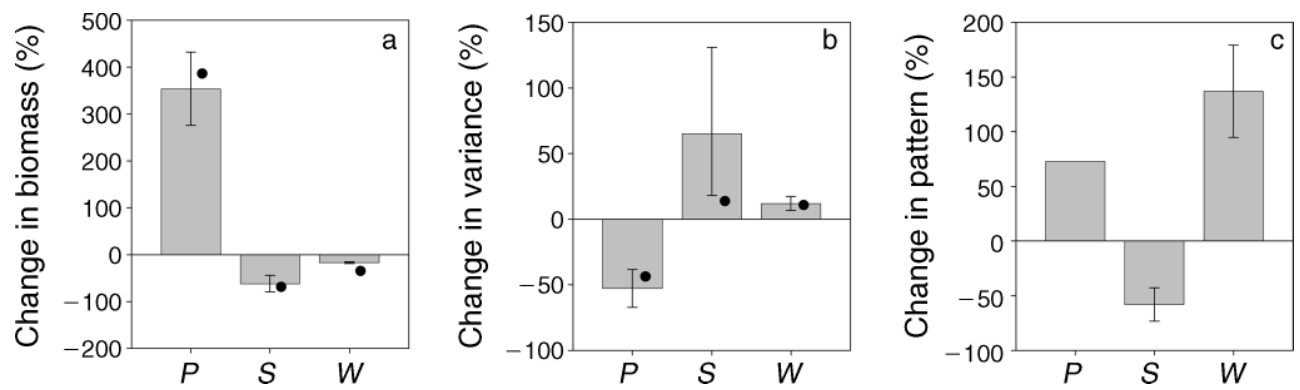

FIG. 3. The effects of plant growth $(P)$, swan foraging $(S)$, and winter mortality $(W)$ on the relative changes between seasonal sampling occasions in (a) the average tuber biomass density, (b) the coefficient of variation in tuber biomass density, and (c) the degree of spatial pattern in the distribution of tuber biomass densities. Error bars denote ranges (highest and lowest values only because sample sizes were low). For reasons of comparison, the average changes in biomass density and coefficient of variation in the $10 \times 10 \mathrm{~m}$ plot (see Methods) are depicted by small dots. 

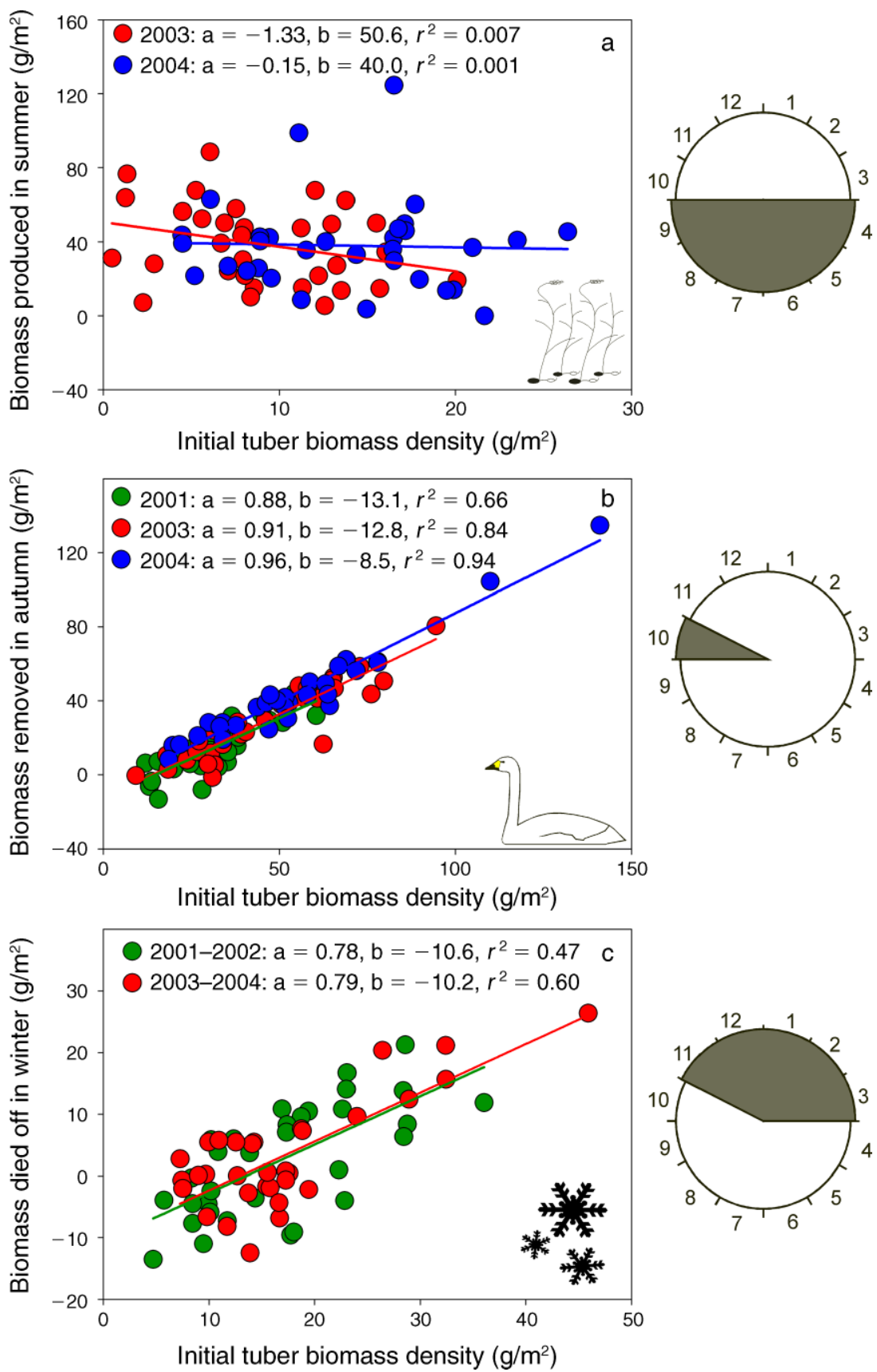

FIG. 4. Changes in the amount of tuber biomass $B$ for different processes in the life cycle of fennel pondweed as a function of initial tuber biomass density $\left(B_{\mathrm{i}}\right)$. (a) Biomass produced in summer $\left(B_{\mathrm{Sep}}-B_{\mathrm{Mar}}, B_{\mathrm{i}}=B_{\mathrm{Mar}}\right)$. (b) Biomass removed by swans in autumn $\left(B_{\mathrm{Sep}}-B_{\mathrm{Nov}}, B_{\mathrm{i}}=B_{\mathrm{Sep}}\right)$. (c) Biomass died off in winter $\left(B_{\mathrm{Nov}}-B_{\mathrm{Mar}}, B_{\mathrm{i}}=B_{\mathrm{Nov}}\right)$. Lines represent linear regressions for which slopes $a$, intercepts $b$, and $r^{2}$ values are given. In these graphs the $x$ - and $y$-axes are not independent (see Appendix B). At right a seasonal clock (1, January; 6 , June; 12, December) is provided. The gray-shaded portion shows the interval between sampling times.

of $y$-axis) and that $88-96 \%$ (regression slope) of the tuber biomass is accessible for the swans (Nolet et al. $2006 a$ ). Winter loss is similarly a function of initial (November) density in which more biomass is lost from a higher initial biomass (Fig. 4c). Tuber biomass densities are measured with an error of $\sim 20 \%$ (as determined in the field; Nolet and Mooij 2002), which may cause spurious correlations between initial density and density changes. However, we determined by simulation that the slopes of such spurious correlations are smaller than the $95 \%$ confidence interval of the observed slopes, except for the correlation between tuber 


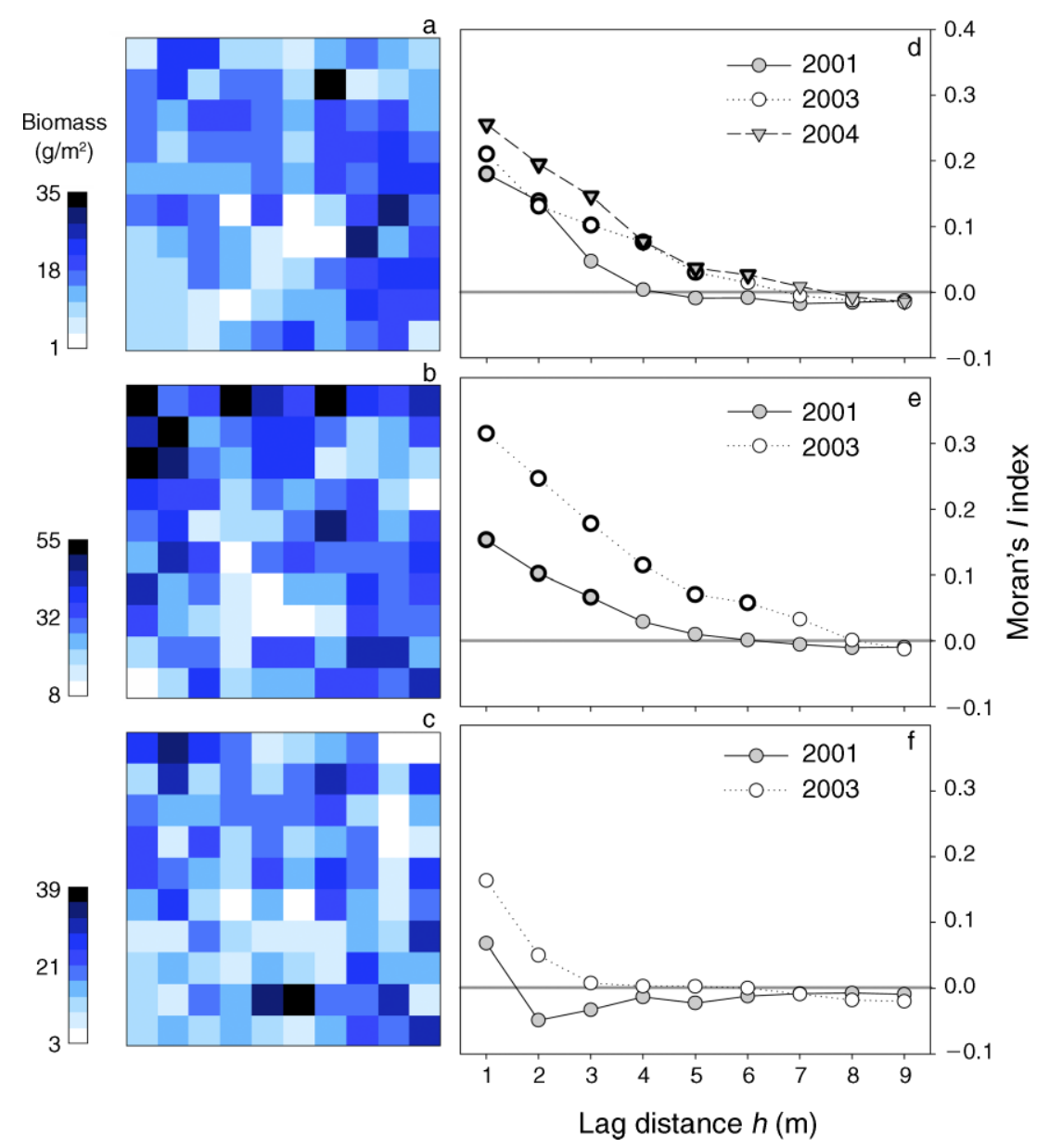

Fig. 5. (a-c) Examples of the distribution of fennel pondweed tuber biomass densities $\left(\mathrm{in} \mathrm{g} / \mathrm{m}^{2}\right)$ in the same $10 \times 10 \mathrm{~m}$ study plot at different times of the year (each square equals $1 \mathrm{~m}^{2}$ ). (a) March, just before the growing season. (b) September, just before the foraging episode of the Bewick's Swans. (c) November, just after the foraging by the swans and just before the winter. The right panels (d-f) depict these small-scale spatial patterns in autocorrelograms, again for the different seasons (d) March, (e) September, (f) November, but now for the data from all years combined. The Moran's I index is a measure for the spatial autocorrelation in food abundance between pairs of points (Sawada 1999). Heavy-outlined symbols indicate that the Moran's $I$ index differs significantly from 0 . Note that a clear spatial pattern in the distribution of tuber biomass densities exists in March and September, but not in November (the latter not being significant).

density in March and the amount of biomass produced in summer (plant growth; see Appendix B). Hence, the reported correlations are no artifacts.

The relative variance in tuber abundance was highest just after the winter. The growth of plants strongly reduced spatial variance (Fig. 3b), as might be expected for a process that is slowed down at higher densities. On the contrary, swan foraging in particular and, to a lesser extent, winter mortality increased the level of variance. (The spatial variance within the $10 \times 10 \mathrm{~m}$ plot, which was used to quantify spatial pattern, changed in similar ways [Fig. 3b].) Both in March and September a clear spatial pattern exists: high densities neighbor with high densities and low densities neighbor with low densities (Fig. 5a-c). This is also reflected in autocorrelograms where the degree of autocorrelation is higher for the first lag distances (Fig. 5d-f). The Moran's $I$ index differed significantly from 0 for lag distances $1-2 \mathrm{~m}$ in March 2002, 1-5 m in March 2003, 1-6 m in March 2004, 1-3 m in October 2001, and 1-6 $\mathrm{m}$ in October 2003. In November, just after the feeding activities of the swans, the spatial pattern has vanished. For none of the lag distances did Moran's $I$ index differ significantly from 0 for both November 2001 and November 2003. We have thus observed that plant growth decreased the degree of variance, whereas it increased the degree of pattern. In contrast, swan foraging increased the degree of spatial variance, whereas it decreased the degree of spatial pattern. Winter mortality enhanced both variance and pattern, demonstrating that effects on variance and pattern are not always inversely related. Similar temporal patterns in spatial variance and spatial pattern emerged when tuber abundance was expressed in numbers rather than biomass densities (results not 
shown), despite the fact that tubers can differ from 20up to 700 -fold in mass.

\section{DisCUSSION}

Spatial variance and spatial pattern each have their own temporal dynamics, with different processes sometimes having different effects on variance than on pattern. For example, swan grazing strongly increased small-scale spatial variance, whereas it strongly reduced the small-scale spatial pattern. In this study system spatial variance seems to be maintained mainly by the feeding activities of the swans, whereas spatial pattern seems to be maintained by winter mortality (and to a lesser extent plant growth).

The direction of the effect of a process on the degree of variance and pattern is not straightforward but depends on specific circumstances. We might, for example, expect that spatial variance decreases if a forager depletes patches down to a fixed threshold level (as swans apparently do, cf. Klaassen et al. 2006a, Nolet et al. 2006a, b). In contrast, we observed that swan foraging strongly increased the level of variance, which is explained by the swans giving-up foraging (and leaving the pondweed bed) before all patches are exploited (Nolet et al. 2006c). Our studies were conducted at a migratory stopover site where the Bewick's Swans maximize their daily energy intake during their relatively short visit (Nolet and Klaassen 2005). At wintering sites swans probably do not maximize their intake rate but satisfy their daily energy requirements, and thus deplete patches down to a much lower threshold (Van Eerden et al. 1997). The effect on the dynamics of spatial variance may however depend on the swans' foraging mode, i.e., whether they use a flexible or fixed patch leaving threshold (Nolet et al. 2006c). A general rule for the effects of a process on variance and pattern remains to be established (Adler et al. 2001), if any such generalization can be made.

In contrast to spatial variance, spatial pattern had disappeared after the foraging activities of the swans, but had reestablished after the winter. Parasitic infections are thought to be an important cause for winter mortality. A limited outreach of infections could actually produce an aggregated spatial pattern, as has, for example, been shown in an insect host-parasitoid system (Maron and Harrison 1997). The exact mechanism of how spatial pattern can reoccur during the winter period remains to be established.

For research on the movement behavior of Bewick's Swans we have also measured tuber abundance at the same study site and in the same years in eight $10 \times 10 \mathrm{~m}$ plots (24 cores/plot; for details see Klaassen et al. 2006a). A lower level of spatial variance was observed at this scale (for example, variance in September was 0.13 and 0.06 for small and large plots, respectively), corroborating a negative scaling relationship between the scale of measurement and the observed level of spatial variance (Wiens 1989, Levin 1992). More interesting, spatial variance had decreased over the winter for these large scale plots (data not shown), which is opposite to the change for small-scale plots. There is thus some indication that the direction of an effect is scale dependent. Consequently, it is pivotal to conduct a study at the right spatial scale. It is a challenge to explain the persistence of spatial variance and spatial pattern at multiple spatial scales.

The term "spatial heterogeneity" has been used for both spatial variance and spatial pattern, causing confusion about what heterogeneity precisely implies (Wiens 2000, Adler et al. 2001). Furthermore many studies are not explicit in whether they study variance or pattern, despite the fact that these are very different forms of spatial heterogeneity. In this study we have shown that spatial variance and spatial pattern are different and independent aspects of a heterogeneous environment that have their own temporal dynamics. Whether a single process is really responsible for maintaining variance or pattern can only be assessed by exclosure studies. In any case, we advocate that it is important to make a distinction between variance and pattern to be able to ultimately understand spatial heterogeneity in a system.

\section{ACKNOWLEDGMENTS}

We are grateful to Staatsbosbeheer for permission to work in their nature reserve. We thank the members of the department of Plant-Animal Interactions for assistance in the field and remarks on earlier drafts. Illuminating commentary was also provided by Rudi Drent, John Fryxell, Niclas Jonzén, and anonymous reviewers. This is publication 4383 of the Netherlands Institute of Ecology (NIOO-KNAW) and publication 511 of the Centre for Wetland Ecology.

\section{Literature Cited}

Adler, P. B., D. A. Raff, and W. K. Lauenroth. 2001. The effect of grazing on the spatial heterogeneity of vegetation. Oecologia 128:465-479.

Bascompte, J., and R. V. Sole. 1998. Spatiotemporal patterns in nature. Trends in Ecology and Evolution 13:173-174.

Beekman, J. H., B. A. Nolet, and M. Klaassen. 2002. Skipping swans: fuelling rates and wind conditions determine differential use of migratory stopover sites of Bewick's Swans Cygnus bewickii. Ardea 90:437-460.

Beekman, J. H., M. R. van Eerden, and S. Dirksen. 1991. Bewick's Swans Cygnus columbianus bewickii utilizing the changing resource of Potamogeton pectinatus during autumn in The Netherlands. Wildfowl Supplement 1:238-248.

Fortin, D., J. M. Morales, and M. S. Boyce. 2005. Elk winter foraging at fine scale in Yellowstone National Park. Oecologia 145:335-343.

Fryxell, J. M., J. F. Wilmshurst, A. R. E. Sinclair, D. T. Haydon, R. D. Holt, and P. A. Abrams. 2005. Landscape scale, heterogeneity, and the viability of Serengeti grazers. Ecology Letters 8:328-335.

Hedenström, A., and T. Alerstam. 1998. How fast can birds migrate? Journal of Avian Biology 29:424-432.

Hutchings, M. J. 1997. The structure of plant populations. Pages 325-358 in M. J. Crawley, editor. Plant ecology. Blackwell, Oxford, UK.

Jonzén, N., B. A. Nolet, L. Santamaría, and M. G. E. Svensson. 2002. Seasonal herbivory and mortality compensation in a swan-pondweed system. Ecological Modelling 147:209-219. 
Klaassen, R. H. G., B. A. Nolet, and D. Bankert. $2006 a$. Movement of foraging Tundra Swans explained by spatial pattern in cryptic food densities. Ecology 87:2244-2254.

Klaassen, R. H. G., B. A. Nolet, and J. De Fouw. 2006b. Intake rate at differently scaled heterogeneous food distributions explained by the ability of tactile-foraging mallard to concentrate foraging effort within profitable areas. Oikos 112:322-331.

Levin, S. A. 1992. The problem of pattern and scale in ecology. Ecology 73:1943-1967.

Li, H., and J. F. Reynolds. 1995. On definition and quantification of heterogeneity. Oikos 73:280-284.

Maron, J. L., and S. Harrison. 1997. Spatial pattern formation in an insect host-parasitoid system. Science 278:1619-1621.

Moran, P. A. P. 1950. Notes on continuous stochastic phenomena. Biometrika 37:17-23.

Nolet, B. A. 2004. Overcompensation and grazing optimisation in a swan-pondweed system? Freshwater Biology 49:13911399.

Nolet, B. A., V. N. Fuld, and M. E. C. Van Rijswijk. $2006 a$. Foraging costs and accessibility as determinants of giving-up densities in a swan-pondweed system. Oikos 112:353-362.

Nolet, B. A., A. Gyimesi, and R. H. G. Klaassen. $2006 b$. Prediction of bird-day carrying capacity on a staging site: a test of depletion models. Journal of Animal Ecology 75:12851292.

Nolet, B. A., and M. Klaassen. 2005. Time and energy constraints in demanding phases of the annual cycle: an example of time limitation in refuelling migratory swans. Oikos 111:302-310.

Nolet, B. A., R. H. G. Klaassen, and W. M. Mooij. 2006c. The use of a flexible patch leaving rule under exploitative competition: a field test with swans. Oikos 112:342-352.

Nolet, B. A., O. Langevoord, R. M. Bevans, K. R. Engelaar, M. Klaassen, R. J. W. Mulder, and S. Van Dijk. 2001. Spatial variation in tuber depletion by swans explained by differences in net intake rates. Ecology 82:1655-1667.

Nolet, B. A., and W. M. Mooij. 2002. Search paths of swans foraging on spatially autocorrelated tubers. Journal of Animal Ecology 71:451-462.

Pickett, S. T. A., and M. L. Cadenasso. 1995. Landscape ecology: spatial heterogeneity in ecological systems. Science 269:331-334.
Rietkerk, M., M. C. Boerlijst, F. Van Langevelde, R. HilleRisLambers, J. Van de Koppel, L. Kumar, H. H. T. Prins, and A. M. De Roos. 2002. Self-organisation of vegetation in arid ecosystems. American Naturalist 160:524-530.

Santamaría, L. 2002. Selective waterfowl herbivory affects species dominance in a submerged plant community. Archiv für Hydrobiologie 153:353-365.

Santamaría, L., and M. A. Rodríguez-Gironés. 2002. Hiding from swans: optimal burial depth of sago pondweed tubers foraged by Bewick's swans. Journal of Ecology 90:303-315.

Sawada, M. 1999. Rookcase: an Excel 97/2000 Visual Basic (VB) add-in for exploring global and local spatial autocorrelation. Bulletin of the Ecological Society of America 80: 231-234.

Sparrow, A. D. 1999. A heterogeneity of heterogeneities. Trends in Ecology and Evolution 14:422-423.

Tenhumberg, B., M. A. Keller, A. J. Tyre, and H. P. Possingham. 2001. The effect of resource aggregation at different scales: optimal foraging behavior of Cotesia rubecula. American Naturalist 158:505-518.

Valone, T. J., and J. S. Brown. 1989. Measuring patch assessment abilities of desert granivores. Ecology 70:1800 1810.

Van Eerden, M. R., J. H. Beekman, M. Smit, and K. Oosterbeek. 1997. Patch use by Bewick's Swans Cygnus columbianus bewickii feeding upon sago pondweed Potamogeton pectinatus in shallow lakes in the Netherlands: variation in exploitation threshold caused by social, environmental and time dependent factors. Pages 111-132 in M. R. van Eerden, editor. Patchwork: patch use, habitat exploitation and carrying capacity for water birds in Dutch freshwater wetlands. Rijkswaterstaat, Directie Ijsselmeergebied, Lelystad, The Netherlands.

Van Wijk, R. J. 1988. Ecological studies on Potamogeton pectinatus L. I. General characteristics, biomass production and life cycles under field conditions. Aquatic Botany 31:211258.

Wiens, J. A. 1989. Spatial scaling in ecology. Functional Ecology 3:385-397.

Wiens, J. A. 2000. Ecological heterogeneity: an ontogeny of concepts and approaches. Pages 9-31 in M. J. Hutchings, E. A. John, and A. J. A. Stewart, editors. The ecological consequences of environmental heterogeneity. Blackwell, Oxford, UK.

\section{APPENDIX A}

A figure showing that study plots are relatively homogeneous in sediment characteristics (Ecological Archives E089-170-A1).

\section{APPENDIX B}

Estimating the slope for spurious correlations between biomass changes and initial biomass density (Ecological Archives E089170-A2). 